\title{
CARACTERIZAÇÃO MECÂNICA DE Leucaena leucocephala POR ULTRASSOM E FLEXÃO
} ESTÁTICA

\author{
Matheus B. Garrido*, Cinthya B. Pedroso, Ryuji Soma
}

\section{Resumo}

A espécie arbórea Leucaena leucocephala (Lam.) de Wit (leucena) é uma árvore invasora que se distribui amplamente pelo território nacional e em diferentes continentes. Uma estratégia adotada pelo estado de São Paulo para conter a sua proliferação foi por meio da flexibilização da legislação ambiental de modo a favorecer a sua supressão. Dessa maneira a madeira proveniente da poda ou de sua supressão é abundante e disponível. Contudo grande parte dela é destinada para aterros sanitários, visto que poucos dados referentes às propriedades mecânicas de sua madeira se encontram na literatura científica que justifiquem uma aplicação tecnológica. Desse modo, o objetivo desta pesquisa de Iniciação Científica foi é a caracterização mecânica da madeira de leucena por meio do ultrassom e de ensaio de flexão estática. Para atingir os objetivos propostos foram realizados ensaios de ultrassom em corpos de prova poliédricos de 26 faces a fim de obter todos os parâmetros elásticos da madeira. Também foram realizados ensaios de flexão estática em corpos de prova com a finalidade de levantar obter dados do módulo de elasticidade na flexão e da resistência à flexão. Desse modo, foi possível obter todos os parâmetros necessários para caracterização mecânica da madeira de leucena.

Palavras-chave: módulo de elasticidade à flexão, resistência à flexão, propriedades elásticas da madeira.

\section{Introdução}

A árvore Leucaena leucocephala (Lam.) de Wit nativa do México e da América Central é considerada mundialmente como uma espécie invasora, estando na lista das 100 espécies invasoras mais agressivas da Global Invasive Species Database de 2013. Há poucos estudos relacionados a caracterização mecânica de sua madeira, uma vez que é considerada uma árvore de uso nãoconvencional para fins estruturais, fato que favorece seu descarte em aterros sanitários ou sua utilização como lenha. Visando favorecer uma aplicação mais sustentável para a madeira de leuceuna, o objetivo desta pesquisa foi a caracterização mecânica da madeira de $L$. leucocephala por meio de ensaios de ultrassom e de flexão estática.

\section{Resultados e Discussão}

Os corpos de prova para os ensaios foram obtidos de diferentes regiões de 6 árvores de leucenas que foram suprimidas.Para os ensaios de flexão estática foram utilizados 18 corpos de prova de seção transversal 20x20 $\mathrm{mm}^{2}$ e comprimento de $420 \mathrm{~mm}$, de acordo com a norma ASTM D198 - 13, o ensaio foi realizado em máquina universal de ensaios (DL 30000, EMIC, Brasil) (Figura 1a). Para os ensaios não destrutivos foram utilizados 18 corpos de prova poliédricos de 26 faces, os quais foram ensaiados com equipamento de ultrassom (EPOCH 1000) e transdutores de compressão e de cisalhamento de 1 $\mathrm{MHz}$ de frequência (Figura $1 \mathrm{~b}$ ).

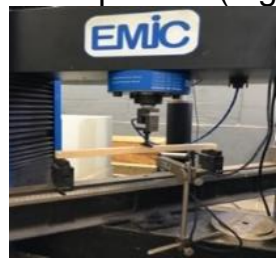

a

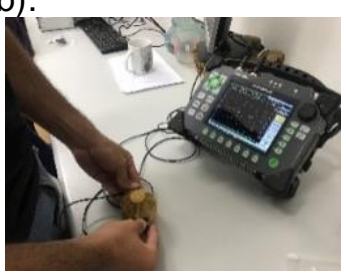

b
Figura 1. Ensaio de flexão (a) e de ultrassom (b).

A partir dos ensaios realizados com ultrassom foram obtidos os módulos de elasticidade longitudinais $\left(E_{L}, E_{R}\right.$, $\mathrm{E}_{\mathrm{T}}$ ) e os módulos de elasticidade transversais (GLR, GLT, $G_{R T}$ ); além dos coeficientes de Poisson (VLR, VRL, VRT, VTR, $\mathrm{V} L T_{\mathrm{T}} \mathrm{VTL}$ ). Com base no ensaio de flexão foi possível obter o módulo de elasticidade $\left(E_{M}\right)$ e a resistência da madeira em flexão $\left(f_{M}\right)$.

Tabela 1. Dados médios e coeficientes de variação (CV) da resistência $\left(f_{M}\right)$ e da rigidez $\left(E_{M}\right)$ obtidos por meio do ensaio de flexão.

\begin{tabular}{ccc}
\hline Parâmetros Elásticos & Média & CV (\%) \\
\hline EM (MPa) & 10632 & 18 \\
fM (MPa) & 104 & 14
\end{tabular}

Tabela 2. Parâmetros elásticos médios e coeficientes de variação $(\mathrm{CV})$ obtidos por meio do ensaio de ultrassom. $\begin{array}{lllllllllllll}\mathbf{E}_{\mathrm{L}} & \mathbf{E}_{\mathrm{R}} & \mathbf{E}_{\mathrm{T}} & \mathbf{G}_{\mathrm{RT}} & \mathbf{G}_{\mathrm{LT}} & \mathbf{G}_{\mathrm{LR}} & \mathbf{v}_{\mathrm{LR}} & \mathbf{y}_{\mathrm{LT}} & \mathbf{y}_{\mathrm{RI}} & \mathbf{v}_{\mathrm{RL}} & \mathbf{y}_{\mathrm{T}} & \mathbf{v}_{\mathrm{TR}}\end{array}$

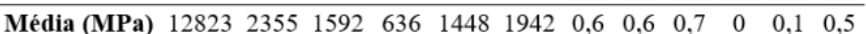
$\begin{array}{lllllllllllll}\text { CV (\%) } & 13 & 15 & 14 & 21 & 14 & 12 & 36 & 37 & 10 & 42 & 39 & 15\end{array}$

A resistência e a rigidez da leucena apresentaram valores próximos aos obtidos na pesquisa de Carrillo, et al., 2011, que obteve valores médios de $109 \mathrm{MPa}$ e 8050 $\mathrm{MPa}$, respectivamente, para essas propriedades, também obtidos por ensaio de flexão estática em três pontos.

A madeira de leucena apresenta valores de propriedades elasticidade próximos aos da madeira Goupia glabra (cupiúba), determinados por ultrassom (Gonçalves et al., 2014), e de Dalbergia latifolia (indian rosewood) e de Cordia dodecandra (ziricote) obtidos por meio de ensaio de flexão e ensaio não destrutivo (Sproßmann et al., 2017).

\section{Conclusões}

A caracterização da madeira de Leucaena leucocephala por ultrassom e por ensaios de flexão estática, mostrou que a espécie apresenta propriedades elásticas compatíveis com espécies empregadas na construção civil e na confecção de instrumentos musicais.

\section{Agradecimentos}

À Profa. Dra. Cinthya Bertoldo e ao Ryuji Soma pela oportunidade e pela partilha de conhecimentos, ao CNPQ pela concessão da bolsa de pesquisa.

Carrillo, Nañez, Garza, Foroughbakhch, Sandoval. Physical and mechanical wood properties of 14 timber species from Northeast Mexico. Annals of Forest Science, 2011.

Gonçalves, R., Trinca, A. J. \& Pellis, B. P. Elastic constants of wood determined by ultrasound using three geometries of specimens. Wood Sci. Technol. 48, 269-287 (2014).

Sproßmann, R., Zauer, M. \& Wagenführ, A. Characterization of acoustic and mechanical properties of common tropical woods used in classical guitars. Results Phys. 7, 1737-1742 (2017). 